\title{
CAPITALISMO COMO PRÁTICA SOCIAL?: OS POTENCIAIS E DESAFIOS DE UMA APROXIMAÇÁO ENTRE O PRACTICE TURN EM TEORIA SOCIAL E A INTERPRETAÇÁO DO CAPITALISMO
}

\author{
Leonardo da Hora ${ }^{1}$
}

\begin{abstract}
Resumo: Este artigo procura apresentar e discutir tentativas recentes em filosofia social de analisar e interpretar o capitalismo, a partir de uma perspectiva praxeológica. O practice turn em teoria social procurou superar o dualismo entre agência e estrutura, ou entre ação e sistema, por meio da noçáo de prática social. Seria possível então interpretar o capitalismo como um tipo especifico de prática social? Para tentar encaminhar essa questáo, explicita-se brevemente, em um primeiro momento, em que consiste o practice turn em teoria social. Num segundo momento, analisa-se e se discute a proposta de Rahel Jaeggi de conceber a economia como uma rede de práticas sociais. Em seguida, expõe-se e se avalia a tentativa de Christian Lotz em ver, no dinheiro, a chave para compreender aquilo que ele chama de esquema capitalista. Por fim, conclui-se, chamando a atenção para os potenciais e desafios ligados ao empreendimento de interpretar o capitalismo em função de uma teoria da prática, sugerindo que um aprofundamento na análise da imaginação especificamente capitalista, vinculando-a com a típica plasticidade e diversidade do capitalismo, possa ajudar a avançar nesse campo.
\end{abstract}

Palavras-chave: Filosofia social. Capitalismo. Prática social.

\section{INTRODUÇÃo}

Interpretar o fenômeno social moderno de produção e circulação de bens e produtos que assumem a forma de mercadorias, assim como o processo de acumulação de riqueza monetária e a dinâmica de expansão da mercantilização e monetarizaçáo de diversos setores sociais, constitui um desafio para a ciência econômica, para a teoria social e para a filosofia. Podemos nos referir a tal fenômeno social como "capitalismo" ou como "economia de mercado". O fato é que duas grandes tendências de análise do que aqui preferimos chamar de capitalismo parecem dominar o cenário.

\footnotetext{
${ }^{1}$ Professor Adjunto do Departamento de Filosofia da Universidade Federal da Bahia (UFBA), Salvador, BA - Brasil. (D) https://orcid.org/0000-0002-0567-0770 E-mail: leonardojorgehp@gmail.com

http://doi.org/10.1590/0101-3173.2020.v43n3.20.p277
}

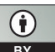

This is an open-access article distributed under the terms of the Creative Commons Attribution License. 
De um lado, temos uma interpretação de viés individualista da "economia de mercado", associada frequentemente às principais correntes da teoria econômica ortodoxa ou neoclássica. Em poucas palavras, o modelo do homo economicus explica a ação, recorrendo a fins, intençôes e cálculos racionais individuais; a ordem econômica é, então, um produto da combinação de interesses individuais de maximização da utilidade. Haveria, por conseguinte, nesse caso, uma subestimação do aspecto social, coletivo e, em alguma medida, inconsciente, das normas e fatores que moldam os interesses e coordenam as açóes dos atores, bem como da própria dinâmica econômica, que muitas vezes ultrapassa a compreensão individual dos agentes sociais.

De outro lado, grosso modo, temos uma leitura do "capitalismo" de viés "estruturalista", "funcionalista" ou "sistêmico", associada a certas vertentes da teoria sociológica e a boa parte do marxismo. Nesse caso, o capitalismo pode ser visto como um "sujeito automático", como um sistema autonomizado, o qual possui uma dinâmica própria de natureza reificada que não apenas ultrapassa a compreensão dos atores, mas também se impôe a estes, enquanto algo "externo" e inescapável, na forma de um processo de dominação impessoal e totalitário, que englobaria completamente o mundo contemporâneo, incluindo o mais íntimo das subjetividades (POSTONE 1996; VIOULAC, 2009; 2013; JAPPE, 2003; KURZ, 2011).

Nesse contexto, certas categorias, como valor, fetichismo e capital, designam os verdadeiros agentes sociais, na forma de macrossujeitos; os humanos, tanto os "capitalistas" quanto os "trabalhadores", são meros portadores de relaçóes sociais capitalistas e as vítimas de suas formas de socialização. Apesar do interesse filosófico de abordar o sistema capitalista como uma totalidade, essa abordagem levanta uma série de dificuldades. Acima de tudo, há o problema inerente a uma abordagem que ignora a questão da ação e das subjetividades e de como estas internalizam e, eventualmente, reagem aos imperativos sistêmicos. Portanto, a análise torna-se demasiado "sistêmica", no sentido de que o capital reina sozinho, o valor se valoriza por si só, e não há mais conflitos sociais, resistências ou alternativas possíveis. Em suma, existe uma espécie de cisão ou abismo entre o âmbito macrossocial e o âmbito dos atores sociais, em proveito do primeiro e em detrimento do último.

Ora, hoje há uma tendência de "dessubstancialização" do social (CORRÊA, 2014), dentro de algumas orientaçóes sociológicas que parecem questionar a perspectiva ontológica que privilegia exclusivamente a abordagem objetivista e sistêmica da realidade social, sem adotar, contudo, uma orientação 
individualista. Na tentativa de superar alguns dos limites das duas leituras mencionadas acima, em relação ao fenômeno capitalista, náo caberia entáo à filosofia social se apropriar, à sua maneira, dessa tendência? Como aponta Stéphane Haber (2012, p. 135), a filosofia social, em função do projeto que a anima, deve buscar se reconhecer em determinadas orientaçóes das ciências sociais. Estas se mostram consumidoras e, sobretudo, produtoras de modelos interpretativos em teoria social, os quais possuem todas as qualidades necessárias para ser classificados como filosóficos.

\section{O PRACTICE TURN EM TEORIA SOCIAL}

A fenomenologia, a sociologia compreensiva, o interacionismo, cada um em seu próprio estilo, contribuíram, ao longo da história da teoria social, para desafiar o modelo da objetividade social como resultado congelado de açóes passadas. Falta a este último precisamente o momento em que o social é efetivamente estruturado, o momento em que a sociedade se estabiliza, onde há participação e engajamento entre os atores envolvidos. Quando parte da sociologia de hoje reivindica o pragmatismo, reavivando em certo sentido esse movimento histórico que surge com os movimentos mencionados acima, é para fazer valer o ponto de vista do ator e do coletivo, os quais, confrontados com problemas e conflitos, improvisam soluçóes, com base, é verdade, em modelos de resolução disponíveis, mas também explorando criativamente as margens de indeterminação oferecidas pelas situaçôes. ${ }^{2}$

Como observado por Andreas Reckwitz, desde a década de 1970, vários autores se dedicaram à construção de uma abordagem praxeológica: Pierre Bourdieu, mas também Anthony Giddens, Garfinkel, Latour, Charles Taylor etc. $\mathrm{O}$ que há de comum entre esses teóricos? Ao tentar uma síntese, Reckwitz (2002, p. 250) define as práticas sociais da seguinte maneira:

Uma "prática" (Praktik) é um tipo de comportamento rotineiro composta de vários elementos, interligados entre si: formas de atividades corporais, formas de atividades mentais, "coisas" e seu uso, um conhecimento de fundo na forma de compreensão, know-how, estados de emoção e conhecimento motivacional. Uma prática - uma maneira de cozinhar, consumir, trabalhar, investigar, cuidar de si mesmo ou de outros, etc. forma, por assim dizer, um "bloco" cuja existência depende necessariamente

2 Para um resumo desta tendência contemporânea em teoria social, ver Corrêa (2014). 
da existência e da interconectividade específica desses elementos, e que não pode ser reduzido a nenhum desses elementos ${ }^{3}$.

É toda a compreensão da ordem social que muda com a abordagem praxeológica. Por exemplo, o modelo do homo economicus explica a ação, recorrendo a fins, intençóes e interesses individuais; a ordem social é então um produto da combinação de interesses individuais. $\mathrm{O}$ modelo do homo sociologicus explica a ação, apontando para as normas e valores coletivos, nomeadamente as regras que expressam uma normatividade social; a ordem social é garantida por um consenso normativo. Por outro lado, a novidade das teorias das práticas sociais consiste em explicar e compreender as ações com base na reconstrução das estruturas simbólicas de conhecimentos, os quais, ao mesmo tempo, "capacitam" e limitam os agentes a interpretar o mundo de acordo com certas formas, e a se comportar correspondentemente. A ordem social, por conseguinte, não aparece como um produto da conformidade das expectativas normativas recíprocas, mas como ancorada em estruturas cognitivas e simbólicas coletivas, em um "conhecimento compartilhado" que enseja uma maneira socialmente compartilhada de dar sentido ao mundo. Além disso, ao contrário da perspectiva intersubjetiva do social, as práticas não pressupóem necessariamente interaçóes.

Uma prática social específica contém formas específicas de conhecimento. Para a teoria da prática, segundo Reckwitz, esse conhecimento é mais complexo que o knowing that. Abrange maneiras de entender, saberfazer, formas de querer e sentir que estão relacionadas uma com a outra, na prática. Em um sentido muito elementar, em uma prática, o conhecimento é um modo particular de "entender o mundo". Essa maneira de entender é amplamente implícita e, em grande parte, historicamente especifica. Além disso, o mundo social é, em primeiro lugar, povoado por práticas sociais diversas que são realizadas por agentes. Os agentes, por assim dizer, correspondem à performance das práticas (que inclui não apenas rotinas corporais, mas também mentais). Como portadores de uma prática, não são nem marionetes nem completamente autônomos. Eles entendem o mundo e a eles próprios, bem como o uso de know-how e de motivaçóes, de acordo com a prática específica.

As teorias da prática são nitidamente menos “intelectualistas" do que as teorias da ação racional, incluindo a ação comunicativa, fortemente ancorada no modelo da argumentação racional. Sob a influência do primeiro Heidegger

\footnotetext{
${ }^{3}$ Salvo indicação em contrário, as traduções das citações são de minha autoria.
} 
e do último Wittgenstein, a prática é mais frequentemente interpretada de acordo com o modelo de um comportamento rotineiro, pré-reflexivo.

Isso não significa necessariamente, no entanto, que não haja a possibilidade de reflexividade ou de mudança social. O primado de um corpo humano não-reflexivo ou, então, de uma reprodução social idêntica não é inevitável. Pelo contrário, os autores que seguem a virada prática (practice turn) enfatizam cada vez mais que, em situaçóes de crise, conflito ou crítica, o social se refaz de forma potencialmente inédita, o que também significa uma tendência para a dessubstancialização do social. A esse respeito, podemos aproximar a virada prática daquilo que Corcuff (2011, p. 14) chama de "novas sociologias", relacionais e construtivistas:

Através de caminhos, às vezes inéditos, às vezes emprestados anteriormente, relacionais (relationnaliste) e muitas vezes construtivistas, as novas sociologias tentaram escapar das armadilhas do substancialismo, apontadas por Wittgenstein. O filósofo observou em nosso relacionamento com a linguagem a tentaçáo de "buscar uma substância que responda a um substantivo", isto é, o fato de considerar a priori que, por trás das palavras que usamos ("sociedade", "o estado", "trabalhador", "família”, "mercado", "gênero", "classe", “interesse", "Identidade”, "subjetividade”, etc.), existem realidades homogêneas, bem definidas e fixas. Contra o substancialismo, as interrogaçôes de inspiração relacional e construtivista dirigem o olhar para as relaçóes sociais, processos históricos e uma pluralidade de usos sociais.

Assim, seguindo aqui Corrêa (2014), pode-se ler a sociologia contemporânea através do seu esforço progressivo de dessubstancialização do social, desde pelo menos os anos 1960-1970. Ervin Goffman, Harold Garfinkel, Norbert Elias, Pierre Bourdieu e Anthony Giddens são apenas alguns dos nomes mais famosos dessa tendência. A principal estratégia comum a todos, a fim de realizar essa árdua tarefa, foi o que Corcuff chamou de "relacionismo", ou seja, a ideia de que a "substância" do social é, na verdade, um todo ou uma rede de relaçóes e interaçóes. Nesse sentido, o "relacionalismo" defende a ideia de que as relaçóes são anteriores aos termos e, portanto, o que Durkheim escreve sobre o fato social tratado como "coisa" é, na realidade, nada mais do que um termo inventado e composto por um universo de relaçóes que lhe são anteriores e constitutivas. Seja através da ênfase em ações interativas in situ, seja em interaçôes face a face, como em Garfinkel (1967) e Goffman (1967), seja ainda pela ênfase em redes de interdependências ou configuraçóes de muitos tipos, como em Elias (1984), ou mesmo na relaçáo dialética entre 
agência e estrutura, como em Bourdieu (1979) e Giddens (1984), o social como coisa parece ter sido um dos principais obstáculos a serem superados, na teoria social contemporânea.

Essa tendência se acentuou ainda mais recentemente, com a crescente influência do pragmatismo. Talvez possamos afirmar que o social deixa de ser o elemento explicativo dos fenômenos, para se tornar o que deve ser explicado a partir de relaçóes, práticas e processos. Além disso, os locais privilegiados de compreensão do social em processo de constituição são situaçôes particularmente problemáticas, isto é, momentos de crise, conflitos ou disputas. Se assim for, a reprodução social é percebida como incerta e indeterminada, onde existem múltiplos regimes de ação. Como tal, a reprodução coloca problemas em todos os momentos às pessoas. Dessa forma, uma teoria da ação deve explicar como os atores resolvem esses problemas. A resolução de problemas ocorre no espaço-tempo da situação problemática e, para resolver os problemas, os atores usam os recursos culturais e práticos disponíveis.

Em outras palavras, parte-se da hipótese de origem pragmática (cf. DEWEY, 2006) de que o social é o que se torna visível e o que se faz, se desfaz e se refaz, através de situaçóes problemáticas, momentos críticos, controvérsias, negociações, crises etc. $\mathrm{O}$ social não é, portanto, o que explica a resolução do problema, mas, ao contrário, é o que emerge das suas formas de resolução. É o resultado provisório e contingente, não a causa. É por isso que, em vez de uma entidade fixa que ajuda a explicar outros elementos potencialmente dinâmicos e fluidos, o social é o resultado sempre aberto e em evolução que emerge da resolução de problemas.

Saímos, assim, dessa análise das diferentes tendências expressadas pela virada prática na teoria social e na sociologia com uma imagem do mundo social marcada pela dessubstancialização, pelo antifuncionalismo, e composta por um conjunto mais ou menos articulado de práticas, açôes e regimes. Em particular, vemos uma concepção de reprodução social que é sempre arriscada, incluindo efeitos imprevistos, complexa e sujeita a situaçóes problemáticas, crises, disputas e conflitos. Nesses momentos, os atores se mostram particularmente capazes de ter em conta os efeitos imprevistos, as críticas e os conflitos, bem como recorrer aos recursos disponíveis, a fim de reformular suas justificativas, práticas, instituiçóes, em uma palavra, o próprio social. 


\section{RAHEL JAEGgi E A ECONOMIA COMO PRÁTICA SOCIAL}

Vimos que essa nova metodologia pressupóe, até certo ponto, um determinado diagnóstico histórico das sociedades contemporâneas. Acreditamos que, se as sociedades analisadas por esses teóricos são sociedades capitalistas, não se pode entender completamente os fenômenos associados a esse tipo de reprodução social, a menos que tomemos em consideração a própria natureza do capitalismo, sua maneira específica de organizar a sociedade. É por isso que a questão de saber o que constitui a especificidade da prática social capitalista se torna aqui importante. Sem querer reduzir todos os fenômenos que podem ser estudados por essas novas sociologias a meros efeitos do capital, parece-nos importante, no entanto, reservar um lugar significativo para a análise da lógica da prática capitalista.

Com efeito, já existem tentativas nesse sentido, no campo da filosofia social: compreender o capitalismo como prática social. No que se segue, iremos avaliar como dois autores, Rahel Jaeggi e Christian Lotz, procuram realizar tal empreitada.

Comecemos por Jaeggi. Em que consiste, então, essa abordagem práticoteórica da economia? Em primeiro lugar, Jaeggi resume as características da noção de prática (social) tal como ela a compreende. As práticas são sequências de açôes simples que podem ser mais ou menos complexas e amplas e possuem um caráter (mais ou menos) repetitivo ou usual. Essas práticas são "sociais", não porque envolvem necessariamente relações interpessoais ou a coordenação de relaçóes sociais. Eles são "sociais", porque só podem existir e serem entendidas no contexto de um domínio de sentido socialmente constituído. As práticas não dizem apenas respeito a açóes intencionais. Devido à sua natureza repetitiva e habitual, elas podem ser baseadas em um conhecimento implícito, até certo ponto, desde que não sejam interrompidas ou confrontadas com problemas. As práticas não são "fatos brutos". Elas devem ser interpretadas e entendidas como algo com certo significado. Isso é, elas são constituídas como práticas, através de interpretaçóes. As práticas são regidas por normas; elas são organizadas em torno de uma ideia essencial do que significa, em geral, realizar essa prática. Finalmente, as práticas têm um telos inerente. Elas são direcionadas para um objetivo que poderá ser alcançado, se o engajamento for real.

Como Joas (1999), Jaeggi considera que uma análise centrada na prática - Joas prefere utilizar a noção de "esquemas estruturais" - enquanto 
resultado dos efeitos intencionais e não intencionais das açóes podem muito bem substituir a análise sistêmica. Na verdade, conceber a economia como um conjunto de práticas sociais não significa que esta seja simplesmente resultado de açôes e intençôes. As práticas são apenas parcialmente intencionais, explícitas e produzidas pela vontade e açóes das pessoas. Elas não são completamente planejadas, mas "emergem". Quando as práticas se "congelam" em instituições (entendidas como estados agregados de práticas), elas podem adquirir suas próprias dinâmicas e assumir uma vida própria, um fenômeno que é difícil de ver para as partes concernidas. Nesse caso, pode ser produtivo reexaminar os chamados fenômenos "sistêmicos", de acordo com um esquema teóricoprático e institucional.

Em seguida, ela observa que as práticas estão inter-relacionadas através de um horizonte comum de interpretação, um horizonte que, por si só, torna essas práticas inteligíveis e funcionais. Esse conjunto de práticas mais ou menos articulado consiste no que Jaeggi chama de "forma de vida". Para Jaeggi, as práticas e formas de vida constituem uma dialética de reprodução e de mudança social, de regras implícitas, as quais, em momentos de crise, se tornam explícitas e exigem reflexão e recriação:

Como resultado, formas de vida (tal como no caso de práticas isoladas) nem sempre são exercidas deliberadamente ou mesmo de modo refletido; podemos participar delas sem planejamento, intençáo ou mesmo sem saber exatamente o que estamos fazendo. Também temos que levar em conta que as práticas sociais e as formas de vida são "materializadas" nas instituiçôes e, ainda mais, "materialmente", na arquitetura, em instrumentos e estruturas materiais que (mesmo que resultem de nossas próprias açôes) nos fazem agir. Portanto: elas estabelecem limites para o que podemos fazer, assim como nos permitem fazer as coisas de uma certa maneira. Práticas e formas de vida, em suma, são dadas, assim como criadas. E eles podem desenvolver uma determinada dinâmica própria. No entanto, são algo que os seres humanos fazem e, portanto, poderiam fazer de outra forma. Isso fica claro assim que um certo conjunto de práticas e auto-compreensões atingem seus limites - quando as coisas não funcionam mais bem. Quando um conjunto de práticas é interrompido, isso não passa mais despercebido: o momento da crise força a reflexão e ajustes de práticas - uma recriação de práticas - que anteriormente eram pressupostas de modo irrefletido (taken for granted) (JAEGGI, 2015, p. 9).

Em que medida, pois, as práticas econômicas são práticas sociais, as quais se agrupam com outros tipos de práticas sociais em uma forma de vida (e 
compartilham as características mencionadas acima)? O que significa conceber o domínio econômico como um domínio de práticas sociais?

Jaeggi considera o campo da economia como aquele que, em poucas palavras, diz respeito à satisfação das necessidades reprodutivas da sociedade, isto é, à produção e à distribuição de bens e serviços. É fácil de ver, por isso, que cada elemento que entra em jogo aqui - por exemplo, a propriedade, a troca mercantil e o trabalho - pode ser visto como uma configuração de práticas e instituiçóes sociais. Jaeggi argumenta que, desse ponto de vista, as práticas relacionadas a questóes econômicas estáo inter-relacionadas ou mesmo interligadas com outras práticas e interpretaçóes não-econômicas. Eles fazem parte do que ela denominou "conjunto" de práticas sociais. Assim, tomando o exemplo da propriedade, Jaeggi observa que diferentes interpretaçóes do título jurídico de "propriedade" são acompanhadas por diferentes práticas de aquisição, conservação e disposição do que é compreendido como propriedade, em uma ordem social. Podemos alienar mais ou menos sem limites, ou não; apropria-se de algo de maneiras diferentes, e certos modos de apropriação valem como criação de propriedade, outros não.

Da mesma forma, se nos voltarmos para o ato de troca mercantil, isso pode ser feito por proprietários privados independentes entrando no mercado, ou não; ele pode basear-se na ideia de reciprocidade ou em ideias de troca de presentes, sem um acordo explícito sobre recompensas imediatas ou futuras. As práticas de troca amparam-se em normas e regras características dessas formas particulares de troca e, portanto, essas formas devem ser inteiramente compreendidas em um contexto de práticas e interpretações. Como mostram as longas discussóes antropológicas sobre o intercâmbio de doaçóes, as próprias ideias de simetria e reciprocidade (para não mencionar as concepçóes básicas de alienabilidade e indiferença ligada à troca de bens) estáo ligadas a um grande número de significados sociais mais amplos.

Jaeggi prossegue, salientando que o trabalho não é simplesmente uma atividade "bruta", mas sim uma prática que existe dentro de uma estrutura social e normativa de reconhecimento. Não é a atividade como tal que constitui um "trabalho", porém, o reconhecimento social da atividade como trabalho e o papel que a respectiva atividade tem, no processo social de cooperação. Cozinhar ou tocar piano pode ser visto como um trabalho ou não, dependendo de quem pratica tais atividades: o cozinheiro ou a dona de casa, o pianista ou o leigo não iniciado. Consequentemente, se é redutor entender as atividades do mercado como simplesmente uma "maximização das preferências" de agentes 
puramente racionais, assim também seria errado reduzir o trabalho a uma "ação instrumental". Trabalhar é uma atividade muito mais rica, composta por uma variedade de atitudes, habilidades simbólicas e comunicativas, marcadas por hábitos, costumes e modos de realização, os quais devem ser compreendidos em um contexto social mais amplo (cf. JAEGGI, 2015, p. 13-14).

Em todo caso, as práticas econômicas provaram ser dependentes e vinculadas a toda uma série de práticas "vizinhas", extraeconômicas. Essas práticas se informam mutuamente, repousam uma sobre a outra e, em alguns casos, são mutuamente dependentes umas das outras. Enfim, constatamos que a própria economia é concebida em um sentido mais amplo, porque não é mais reduzida a atitudes comportamentais visando à maximização da utilidade que busca responder a interesses estreitamente definidos.

Se é assim, surge a questão de saber se esse caráter situado das práticas econômicas ainda é válido para as sociedades capitalistas. Não é uma característica definidora da sociedade capitalista que "a economia" (e a racionalidade econômica) se separou da rede de práticas sociais? Ou, como ressalta Karl Polanyi (2001): não é justamente o processo de "desincrustaçáo" (disembeddedness) da economia e sua autonomizaçáo para fora de qualquer contexto social que constitui o traço particular (e ameaçador) das sociedades capitalistas? O capitalismo não seria, entâo, uma "forma de vida", mas ameaçaria todas as formas de vida com sua dominação (e a dominação do trabalho abstrato e morto).

Jaeggi reconhece claramente que as práticas econômicas e as instituiçôes do capitalismo assumem uma forma determinada e determinante, como a propriedade privada dos meios de produção, a existência de um mercado de trabalho "livre" e uma acumulaçáo de capital orientada para o "ganho", em vez de ser direcionada para as necessidades. As relaçôes econômicas não só parecem ultrapassar outros aspectos da vida, mas também parecem desenvolver suas próprias dinâmicas que vão além dos fins subjetivos e do controle de seus participantes e que não podem ser confirmadas por eles, coletivamente. Isto é o que normalmente é referido como o caráter sistêmico da economia capitalista. Todavia, Jaeggi (2015, p. 20) enfatiza:

As atividades envolvidas ainda são práticas, baseadas em normas, agregadas em instituiçóes e envolvidas no contexto prático mais amplo de uma forma de vida - mesmo se elas possam vir a ser "práticas fracassadas" em certo sentido. A organização capitalista da economia apenas se apresenta ela mesma como "desincrustrada" ou "desnormatizada", na medida em que sua 
dinâmica consiste na dissolução dos limites éticos tradicionais enquanto expressos institucionalmente, por exemplo, em regulamentos e limitaçóes pré-modernas, baseados nas corporaçôes, da atividade econômica. Mas, argumento, isso também constitui sua própria e nova normatividade. $\mathrm{O}$ que está sendo designado aqui é apenas a ausência de um ethos específico e a substituição de uma norma e seu quadro institucional por outro - um ethos que se apresenta como eticamente "neutro" e baseado em preferências racionais e maximização de utilidade [...] Mesmo a ideia de troca universal, como eu indiquei, pressupóe, tanto quanto constitui uma forma de vida. Mesmo a prática que esconde seu "caráter de prática” ainda é uma prática [...] o "contexto da falta de contexto" ainda é um contexto. E o ethos de abolir relaçóes e restriçóes éticas substanciais, como os que foram quebrados no curso das instituiçóes econômicas "modernas" ou capitalistas (que são tanto um pressuposto quanto um efeito de tais relaçóes), é ainda um ethos - o ethos do capitalismo.

A partir dessa caracterização das práticas capitalistas como algo que mascara seu caráter normativo e socialmente instituído, Jaeggi (2015, p. 20 21) pode conceber sua crítica da forma de vida capitalista:

Em vez disso, se as práticas econômicas são conceitualizadas como práticas dentro de um contexto mais amplo de práticas, como parte do tecido sociocultural da sociedade e se mesmo a dinâmica aparentemente inacessível e auto-movente dos processos econômicos deveria, em princípio, ser capaz de ser pensada como resultado, em qualquer caso, de uma cadeia complexa de práticas, o que surge é antes a perspectiva de renovar uma crítica do capitalismo como uma ordem social irracional em certo sentido [...] Parece haver algo de errado com uma ordem social que se baseia em uma ética que, ao mesmo tempo, oculta e se universaliza como "neutra". E parece haver algo errado com práticas que não enxergamos como práticas e que são constituídas de tal forma que o fato de sua artificialidade (de serem feitas) é ocultado, como é o caso das forças econômicas que dirigem nossas vidas no capitalismo.

As observaçóes de Jaeggi sobre o caráter social e historicamente construído de muitos pressupostos interpretativos das práticas econômicas me parecem corretas e justas. No entanto, o problema com essa análise é que ela não fornece adequadamente uma concepção específica da prática capitalista. É verdade que Jaeggi designa certos traços característicos da economia capitalista, como o trabalho "livre", a busca de lucro ou a propriedade privada dos meios de produção, contudo, ela não os analisa realmente. Além disso, não estabelece uma clara distinção entre troca mercantil e economia capitalista. É por isso 
que seu critério de crítica do capitalismo é bastante vago, reproduzindo a crítica geral da alienação, sem especificá-la em relação às condiçóes capitalistas de trabalho, consumo etc. Ela afirma que a prática capitalista tem sua própria normatividade, apesar de seu aspecto neutro, entretanto, nem sempre é fácil entender em que essa normatividade consiste.

Será que basta dizer que as práticas capitalistas não estão isoladas e pressupóem outras práticas sociais? Isso não poderia nos levar a perder de vista justamente o essencial - justamente aquilo que caracteriza, de modo preciso, a forma social capitalista? Neste ponto, eu gostaria de colocar a seguinte questão: o que, ao mesmo tempo, haveria de fundamentalmente específico e problemático na prática social capitalista, que nos permitiria melhor pensar as diversas crises que assolam os nossos tempos? Isto é, se, como Jaeggi argumenta, as práticas não são fatos, qual o horizonte comum de sentido e de interpretação que tornam as práticas capitalistas (a sua forma de vida) inteligíveis e funcionais?

Ora, a meu ver, a força da abordagem em termos de prática social reside justamente nesse esforço de reconstrução das estruturas simbólicas de conhecimentos que, ao mesmo tempo, capacitam e limitam os agentes a interpretar o mundo segundo determinadas categorias ontológicas, e a se comportar correspondentemente. Apesar da força da abordagem de Jaeggi, creio que falta a ela uma consideração mais profunda e sistemática daquilo que aparece empiricamente como a hybris da dinâmica capitalista. A minha hipótese é que a única maneira de fornecer um critério mais preciso para a reconstrução do horizonte simbólico e interpretativo da prática capitalista é levar em consideração a centralidade e a importância fundamental do fenômeno monetário, na economia capitalista. Para tanto, tomarei um atalho e abordarei o trabalho de Christian Lotz.

\section{Christian LotZ E O DiNheiro COMO ESQUema CAPITALISTA}

A ideia central que Christian Lotz defende é a de que, para além da diversidade das fases do capitalismo e das condiçôes mais concretas de institucionalização de sua prática específica, há uma socialização básica, a qual tem a ver com o dinheiro como valor em processo. Sua sugestão é que isso não deve ser tomado em um sentido estritamente econômico, mas também em termos de uma perspectiva teórica mais geral, abstrata e "transcendental". Assim, uma definição meramente empírica do capitalismo deve ser superada; 
por exemplo, aquela que o define como um sistema econômico composto de características como a propriedade privada dos meios de produçáo, a existência de um mercado de trabalho "livre" e uma acumulação de capital orientada para o lucro. Como argumenta Jaeggi, as práticas envolvem interpretaçóes, elas não são "fatos brutos". Esses fatos devem ser interpretados e entendidos como algo. Além disso, as práticas são regidas por normas. Podemos insistir na pergunta: quais interpretaçóes e quais normas perpassam as práticas capitalistas?

Para melhor esclarecer esse ponto, aprofundaremos a proposta desenvolvida por Lotz. Em resumo, a tese de base de Lotz é a de conceber o dinheiro capitalista como um esquema (schema), no sentido kantiano do termo. Na linha de Sohn-Rethel, ele propóe uma transformação materialista e sócio-histórica da Crítica da Razão Pura, ao atribuir ao dinheiro esse papel:

Para repetir brevemente o ponto principal, para Kant, as condiçóes de possibilidade de representação da realidade são dadas através de uma estrutura racional que determina todas as experiências e possibilita a nossa representação em geral. A estrutura mais abstrata é a de um objeto como tal. Antes que possamos ter alguma experiência, nossa razão projeta antecipadamente, por assim dizer, um "super-conceito" da realidade, que é o conceito de objeto ou objetualidade (objecthood). As categorias que Kant determina como a parte pura da razáo, como mostrei na introdução, constituem essa objetualidade e, assim, permitem que os humanos se refiram a algo no mundo e encontrem objetos específicos, como essa mesa ou aquela casa. É claro que a objetualidade deve ser de natureza universal e, como tal, não é idêntica às coisas empiricamente encontradas em nosso mundo; em vez disso, é o que torna possível qualquer representação de objetos empíricos. Se voltarmos agora para Marx, não só vemos os vestígios do conceito kantiano de categoria, mas também vemos que Marx pensa o dinheiro de forma muito parecida. Podemos ver que Marx pensa no dinheiro como algo que é, por assim dizer, a substituição social do objeto epistemologicamente definido, isto é, da objetualidade (LOTZ, 2014, p. 44).

Por que o dinheiro? Porque, de acordo com Lotz, Marx define o dinheiro como o objeto de referência na economia capitalista; ele torna-se uma força universal, bem como o mediador universal da vida social. Contrariamente às abordagens neoclássicas do dinheiro, Marx (1986) argumenta que o dinheiro é o resultado necessário do processo de troca, caso contrário, as contradiçôes internas da forma-valor simples não poderiam ser resolvidas. Em suma, o dinheiro é o resultado da universalização da forma-valor, através da qual os produtos estabelecem sua permutabilidade. $\mathrm{O}$ dinheiro não é mais do que 
uma forma específica de relação social, a saber, a forma em que os indivíduos são socializados e sintetizados como indivíduos sociais, por meio de algo externo e auto-objetivado ou reificado, o que transforma essas relaçóes em algo abstrato. Como o dinheiro é a coisa universal e verdadeiramente existente que estabelece a totalidade da sociedade, ele estabelece todas as relaçóes sociais, bem como a relação que os indivíduos têm com essa totalidade como uma relação externa. Segundo Lotz, essa ideia marxiana é a tradução material do conceito kantiano de coisidade, que também é definido como independente em relação à realidade fugaz.

Consequentemente, o dinheiro não é senão essa universalidade da equivalência. Sem dinheiro, o valor de uma mercadoria náo pode ser relacionado a outra. Essa forma geral de valor realmente começa a existir, através de indivíduos que trocam seus produtos. Inconscientemente e sem saber, esses indivíduos reproduzem a relação social com cada ato de troca, estabelecem isso como uma abstração real, daí a ideia central:

Marx transfere essa estrutura da primeira Critica kantiana para uma estrutura materialista dentro da qual o dinheiro é determinado como coisidade (thinghood), já que ele determina o quadro sob o qual os indivíduos podem estabelecer e se referir a entidades. Como o dinheiro permanece como a única coisa que existe de forma independente em todas essas trocas, ela se estabelece como a "força transcendental" por trás de tudo, mesmo se Marx já não conceba isso como uma estrutura universal da razão, mas sim como uma forma social historicamente determinada. A forma-dinheiro é aqui o esquema geral que controla e enquadra todos os relacionamentos e todas as referências a objetos em uma totalidade social (LOTZ, 2014, p. 83).

O dinheiro não é aqui uma entidade "fixa"; podemos ver que o dinheiro não é uma coisa (papel, símbolos etc.). Com efeito, o dinheiro é uma forma social que rege o modo como os indivíduos podem ser vinculados uns aos outros e, ao fazê-lo, adquire uma "força transcendental" que molda "fenomenologicamente" ${ }^{4}$ a realidade e determina o que é significativamente acessível na sociedade. Na verdade, o contato sensível com as coisas só passa a valer como modo de conhecimento do mundo depois de inserir-se na trama

${ }^{4} \mathrm{O}$ uso do termo "fenomenológico" aqui tem um sentido bastante amplo. Tem sobretudo o sentido de delimitar as condiçôes de percepção e significação que marcam nossa experiência com os objetos que nos aparecem (enquanto fenômenos) no mundo. Não terei condiçôes aqui, contudo, de realizar uma confrontação mais detida do trabalho de Lotz com a tradição especificamente fenomenológica, de Husserl a Levinas, já que isso nos levaria muito longe e extrapolaria o escopo deste artigo. 
regrada de nossas práticas sociossimbólicas. Muito do que julgamos existir ou acontecer no mundo depende, sem dúvida, do que vemos existir ou acontecer no mundo. No entanto, isso náo basta para compreendermos o que estrutura nosso mundo social. Ter sensaçóes visuais é um fenômeno físico, ver algo e ver algo como algo é exercitar técnicas particulares de comércio simbólico com o mundo, segundo a forma "Vejo X como Y". O dinheiro capitalista opera justamente essa forma de darmos significado aos objetos que encontramos no mundo.

Mesmo que o dinheiro permaneça "escondido" por trás de um véu de experiência empírica e do aspecto natural das coisas, ele, no entanto, define objetos e assim se estabelece como uma força quase metafísica por trás de tudo, determinando todas as relaçôes sociais possíveis. Lotz nos dá um exemplo. Quando vamos ao supermercado, podemos ver, ao menos se estamos no mundo ocidental, uma variedade de produtos. Um supermercado médio em um país ocidental possui cerca de 40.000 itens diferentes. Em seu aspecto empírico, esses produtos parecem ser diferentes, uma vez que suas propriedades naturais diferem. Alguns são maiores, alguns são menores e todos estão lutando pela nossa atenção, através de uma série de outras propriedades, como cor, forma, embalagem e símbolos. Entretanto, o que torna todos esses objetos idênticos e os define como objetos, nesse espaço? É, antes de mais nada, o fato de que eles podem ser comprados com dinheiro ou, em outras palavras, que podem ser trocados por dinheiro. O dinheiro é, portanto, aquilo que fornece o significado daqueles objetos ocuparem aquele espaço no supermercado, enquanto "mercadorias" trocáveis por certa soma monetária. Vemos objetos diferentes como indistintamente mercadorias (segunda a fórmula "vejo $\mathrm{X}$ como Y”), graças à força transcendental do dinheiro capitalista.

Pode-se objetar que a identificaçáo exclusiva dos objetos com mercadorias é injustificada, porque simplesmente não parece ser verdade - de um ponto de vista empírico - que tudo o que encontramos ao nosso redor seja uma mercadoria. Essa afirmaçáo, evidentemente, é correta enquanto tal, já que, segundo o exemplo de Lotz, ainda caminhamos por parques e florestas aos domingos, nas montanhas durante nossas férias ou podemos até mesmo viajar para ver o mar. No entanto, o argumento que ele apresenta está em um nível diferente, uma vez que a tese é de que não podemos mais acessar esses objetos de conhecimento, percepção, ação etc., sem a forma potencial que regula seu acesso como objetos sociais. Poderíamos - e muitas vezes esse é o caso - imaginar e pensar nessas coisas enquanto mercadorias. $\mathrm{O}$ sentido 
do oceano Atlântico hoje é certamente determinado pela possibilidade de que possamos explorar seus recursos naturais, usá-lo para navios, comércio ou por razôes militares. Assim:

$\mathrm{O}$ argumento aqui apresentado, portanto, baseia-se em uma teoria social, uma vez que precisamos mostrar que a compreensão e o ser das entidades que nos cercam hoje são constituídos por mercadorias em sua formadinheiro. É claro, então, que precisamos preparar uma compreensão das mercadorias como algo que é uma forma e não um objeto, dado que as mercadorias não são simplesmente objetos que podemos pegar com nossas máos, caminhar sobre ou ver com nossos olhos; em vez disso, elas existem principalmente na forma de relaçóes sociais. Consequentemente, a compreensão dessas entidades como potencialmente constituída pela forma-dinheiro é a condição transcendental de sua possibilidade de aparecer no mundo em que vivemos (LOTZ, 2014, p. 33).

Percebe-se, portanto, que Lotz procura construir, no fundo, por meio da abordagem da forma-dinheiro, um conceito de "transcendental prático", posto que a armação transcendental condiciona e é condicionada social e historicamente por um conjunto de práticas sociais. É nesse ponto que ele pretende se diferenciar do idealismo kantiano e se aproximar de um Marx lido com as lentes de Sohn-Rethel. A influência deste último sobre o trabalho de Lotz é notória. Para Sohn-Rethel (1989), na compreensão da prática social capitalista, o que conta não é a motivação psicológica dos atores, mas a existência de uma espécie de elemento a priori muito geral, segundo o qual as coisas do mundo são vistas como homogêneas, comensuráveis, intercambiáveis, em suma, como submetidas ao poder do dinheiro. $\mathrm{O}$ capitalismo não é o que se produz, quando as pessoas se dedicam a empreendimentos privados com base em seus traços pessoais, mas sim quando o mundo se "abre" aos agentes sociais, ao mesmo tempo como algo que pode ser racionalmente dominado e como algo composto de entidades descontínuas e homogêneas. Não se trata de explicar o capitalismo por paixôes eternas, como o egoísmo ou a sede de riquezas, porém, mostrar que é uma nova maneira de ver o mundo, ancorada em práticas materiais precisas (a troca mercantil, notadamente), que possibilitou implementá-la.

Nesse sentido, Sohn-Rethel observa que, quando dois indivíduos realizam um ato de troca, eles têm de pressupor implicitamente ou praticamente uma série de interpretaçóes sobre o mundo e sobre os objetos. Como vimos com Jaeggi, a troca de produtos náo é um fato bruto e tal 
conjunto interpretativo pode ser sintetizado pela noção de abstração real. Ora, Sohn-Rethel compreendeu, em uma época que quase ninguém percebia isso, que, para Marx, a característica mais essencial do capitalismo é a abstração que ele impóe à vida social. Assim, quando trocamos dois produtos, pressupomos que esses produtos não apenas são qualitativamente homogêneos e, portanto, comparáveis, só diferindo entre si em termos de quantidade, mas também que, no processo de troca, eles não sofrem nenhum tipo de modificação material. O espaço e o tempo implicados na atividade da troca se tornam, da mesma forma, médiums abstratos e homogêneos, tempo cronológico infinito e espaço ilimitado.

Nessa perspectiva, para Lotz e Sohn-Rethel, as mercadorias não são objetos ontologicamente fixos, como as árvores ou as obras de arte (que podem tornar-se mercadorias); na realidade, o que queremos dizer, quando nos referimos a mercadorias, é uma forma. Isto é, encontrar "objetos" no capitalismo significa, portanto, encontrá-los de forma esquematizada, nomeadamente como mercadorias. Na verdade, a própria forma de mercadoria depende da forma-dinheiro. Por conseguinte, o que realmente encontramos através do esquema é a forma social com a qual as entidades se tornam acessíveis a nós, no capitalismo. No entanto, a forma como essas coisas aparecem como mercadorias permanece oculta para nós e precisa de exposição.

Ou seja, o que aparecia a Kant como as condiçóes transcendentais da experiência de um sujeito universal do conhecimento, aparece a Lotz, na esteira de Sohn-Rethel, como as condiçóes transcendentais práticas (e, portanto, não fundamentadas em um suposto sujeito universal, mas sim em práticas situadas social e historicamente) da experiência significativa e perceptiva de indivíduos socializados no capitalismo. Isto é, para que algo possa ser significado de uma certa perspectiva prática, é preciso que o espaço das possibilidades de significação que essa perspectiva delimita seja apresentado por meio da armação transcendental que a sustenta. O dinheiro, no capitalismo, cumpre precisamente essa função de transcendental prático - que não é meramente empírica - de conformar o espaço daquilo que pode ter significação para nós. Tudo que pode ter significado para indivíduos socializados no capitalismo deve ser conformado ou, digamos, "passar pelo filtro" da forma-dinheiro. O dinheiro enquanto equivalente universal constituiria, assim, o nosso horizonte simbólico e interpretativo, ao operacionalizar na prática o esquema do "ver algo como mercadoria”. Aquela força transcendental que Kant via como razão pura, Lotz reinterpreta em termos práticos e sociais como forma-dinheiro. 
Pode-se, contudo, dizer que o dinheiro não é decisivo e que esse argumento não tem significado, que encontramos o dinheiro ao longo de toda a história e em praticamente todas as sociedades envolvidas na prática da troca. Este é, sem dúvida, o caso, mas nessas sociedades o dinheiro não existe como a forma pela qual todas as relaçóes sociais são mediadas (pelo menos potencialmente).

Uma consequência desse esquema capitalista é a dinâmica do espaço e do tempo. A troca de produtos sempre foi associada a um contexto específico do espaço e do tempo; todavia, com o estabelecimento do dinheiro como a forma de valor universalmente existente, a relação com o espaço e o tempo em si torna-se abstrata e independente das condiçóes locais, uma vez que a forma-dinheiro pode se impor a qualquer conteúdo. Tudo pode ser trocado por tudo. Consequentemente, náo é mais importante saber quem troca o que, ou quando e onde o comércio ocorre. Do mesmo modo, a constituição desse esquema transcendental prático que estrutura e conforma tudo o que tem significado no capitalismo está profundamente ligado ao tempo. À medida que o dinheiro é estabelecido como o universal que regula e estabelece todas as relaçóes sociais capitalistas, o tempo, agora subsumido sob o dinheiro, torna-se (i) socialmente universal, (ii) mensurável e (iii) a unidade que regula todo o intercâmbio, na forma de produção e circulação do tempo. O trabalho sob o capitalismo é constituído como trabalho abstrato e como tempo de trabalho. A capitalização da força de trabalho, pode-se dizer, não só leva a uma forma abstrata de trabalho, mas também a uma forma de medida temporal abstrata. Assim, com o advento do dinheiro capitalista, o espaço e o tempo são fundamentalmente reconstituídos sob uma forma diferente.

Na narrativa de Lotz, a expansão capitalista é possível, porque o tempo se torna socialmente abstrato, um princípio universal de tudo, e, em combinação com a subsunção do trabalho sob o valor em processo, essa expansão pode assumir uma forma espacial (corpos, movimentos, áreas geográficas, limites etc.) e temporais (vida individual, gerações, história etc.). A subsunção do trabalho sob o capital é idêntica à monetização da vida como tal.

Do ponto de vista de uma abordagem praxeológica do capitalismo que é o nosso foco aqui -, o que é importante notar é que Lotz (2014, p. 57) critica uma definição meramente "empírica" ou "positivista" do capitalismo:

Deve ter ficado claro agora que não argumento com base em um conceito histórico, sociológico ou positivista do capitalismo. É comum na maioria da literatura sobre Marx e o capitalismo definir o último como um 
sistema, dentro do qual os meios de produção são de propriedade privada [...] Mesmo que assumamos que esses quatro critérios fazem sentido [...] Eu não penso que o capitalismo é algo que podemos "definir", como se fosse algo dado, porque o termo "capitalismo" se refere a uma totalidade que, como tal, só pode ser reconstruída dialeticamente, o que nesse ponto significa que precisamos analisar o capitalismo como um sistema de determinaçóes categoriais. Essas determinaçóes categoriais são determinaçóes da objetualidade econômica e não podem simplesmente ser explicadas empiricamente, como eu argumentava nos primeiros capítulos.

O que Lotz está tentando argumentar aqui é que uma correta definição do capitalismo deve levar em conta os esquemas interpretativos (ou "transcendentais", na terminologia dele) pressupostos pela prática capitalista. Por isso, não podemos nos contentar com uma análise meramente empírica desse fenômeno social. Nesse sentido, ele se aproxima da perspectiva praxeológica de Jaeggi, embora não utilize explicitamente tais termos. Aliás, esse aspecto é o que caracteriza, segundo ele, a natureza "filosófica" de sua abordagem do capitalismo:

Por isso, minha abordagem é filosófica no sentido de que a investigação do quadro categórico que ofereço é o que torna possíveis as quatro definiçóes que Cudd enumera. O capitalismo náo é, como no conceito positivista de Cudd, algo que tem quatro propriedades; em vez disso, refere-se a um sistema sob o qual toda entidade social que cai sob ele é determinada pelo capital compreendido como o que Marx chama de "dinheiro em processo" [...] O capital, em outras palavras, náo é nada que possamos segurar em nossas mãos; em vez disso, é puro processo, relação, fluidez (LOTZ, 2014, p. 59).

De acordo com essa perspectiva, o dinheiro aparece no capitalismo como o meio transcendental que medeia todas as açóes e todas as relaçóes de poder no capitalismo. É claro que encontramos, no capitalismo, um conflito entre trabalhadores e capitalistas, mas essa afirmação, como tal, não possibilita a compreensão do quadro categórico que orienta as açóes capitalistas e possibilita essa divisão. Os conflitos sociais em geral não são específicos da formação social capitalista, porque existem em muitas outras sociedades; donde os limites de uma abordagem exclusivamente orientada para o conflito, pela luta de classes e assim por diante.

Lotz está muito mais preocupado em compreender os pressupostos interpretativos do que ele chama de esquema capitalista. Ora, vimos, no começo 
deste artigo, que a abordagem praxeológica procura explicar e compreender as ações com base na reconstrução das estruturas simbólicas de conhecimentos, os quais, ao mesmo tempo, capacitam e limitam os agentes a interpretar o mundo de determinada maneira, e a se comportar correspondentemente. No caso do capitalismo, segundo a hipótese de Lotz, o dinheiro (enquanto um tipo específico de prática e relação social) assume essa função primordial de fornecer um padrão ou quadro de interpretação e de atribuição de sentido ao mundo, a ponto de alterar nossas concepçóes de tempo e espaço.

\section{COMPREENDER A REPRODUÇÁO AMPLIADA DO CAPITAL DE UM PONTO DE VISTA PRAXEOLÓGICO: EM DIREÇÁO A UM CONCEITO DE IMAGINAÇÁO CAPITALISTA}

Apesar do seu interesse e fecundidade, poderíamos ainda assim questionar alguns pontos da proposta de Lotz. É digno de nota, particularmente, o fato de que a dinâmica capitalista é frequentemente vista como um fato dado, como um fenômeno social totalitário, absoluto, sem falhas e sem resistências ou conflitos aparentes. A insuficiência da abordagem conflitual não pode conduzir à sua completa supressão. Lotz (2014, p. 58-59) afirma, por exemplo:

Por conseguinte, concordo com o ponto de Arthur (contra Lebowitz) de que também não devemos interpretar a totalidade social sob o capitalismo como uma totalidade de dois lados que é constituída através do trabalho e do capital, na medida em que a forma de trabalho sob o capitalismo é desde o início apropriada pelo capital como trabalho assalariado.

Nesse ponto, ele se aproxima de alguém como Postone ${ }^{5}$ e de uma abordagem excessivamente sistêmica e "substancialista" do capitalismo, à qual o modelo praxeológico poderia precisamente funcionar como antídoto, uma vez que, como vimos, este procura dar mais espaço ao âmbito da ação social (e às crises, críticas e conflitos) e a uma visão dessubstancializada do social, sem cair numa perspectiva individualista.

Nesse sentido, apesar de promissora, a via de uma abordagem centrada na prática capitalista ainda precisa avançar, para se mostrar como uma alternativa real aos modelos tanto individualista quanto sistêmico. Para tanto, talvez um bom ponto de partida seja a compreensão da relação entre a prática capitalista e a diversidade e plasticidade da dinâmica capitalista, tal como diagnosticadas

\footnotetext{
${ }^{5}$ Desenvolvi uma leitura crítica do trabalho de Postone em DA HORA PEREIRA (2018).
} 
por alguns trabalhos no campo da economia e da sociologia. ${ }^{6}$ Afinal, se o social é o que se torna visível e o que se faz, se desfaz e se refaz, através de situaçóes problemáticas, momentos críticos, controvérsias, negociaçóes, crises etc., e se essa maneira de compreender o social se torna especialmente premente, nas sociedades contemporâneas, devemos insistir que não se pode entender completamente a dinâmica capitalista, através de uma teoria da prática social capitalista que deixe de dar conta do que denominarei imaginaçâa capitalista.

Ainda que de modo esquemático, indicarei aqui, para concluir, as linhas gerais do que poderia se delinear como uma abordagem alternativa da prática social capitalista. O ponto de partida é o de que a reprodução ampliada do capital, a tendência de acumulação infinita, centrada na compreensão do dinheiro capitalista como valor em processo (na fórmula de Marx: D-M-D'), não pode ser entendida como a trajetória autônoma de um grande sujeito que se move sozinho. Ela deve ser compreendida como a de uma reestruturaçáo constante do existente pela lógica de acumulação de riqueza abstrata (dinheiro), a qual dá origem a vários fenômenos específicos que são difíceis de reduzir a uma trajetória linear. Os capitalistas, portadores dessa lógica abstrata, devem assimilar as situaçôes e enfrentar as circunstâncias e os ambientes um a um. Essa tensão às vezes explode em conflitos, choques e crises. Todo esse movimento de reprodução ampliada do capital não é automático.

Assim, se a dinâmica do capitalismo não é completamente contingente, ela apresenta, contudo, muitas inovaçóes, desvios, retomadas - a despeito de, ao mesmo tempo, ela continuar reproduzindo os processos históricos de acumulação, exploração, dominação, instrumentalização etc. - de modo que essa plasticidade precisa ser levada em conta seriamente por uma teoria crítica do capitalismo.

Em face da diversidade espácio-temporal dos regimes de acumulação, regulação e exploraçáo do(s) capitalismo(s), cabe a pergunta: como isso foi possível? Aliás, como isso tem sido sistematicamente possível? Acredito que uma abordagem fundamentalmente sistêmica e substancialista - que passa por cima e relega ao segundo plano as capacidades e habilidades socialmente produzidas dos atores - não é capaz de nos oferecer subsídios para responder a

\footnotetext{
${ }^{6}$ Sobre esse assunto, destaco os diversos trabalhos teóricos e empíricos da Teoria francesa da Regulação sobre a diversidade espácio-temporal do capitalismo, no campo da economia (ver, por exemplo, AMABLE, 2005; BOYER, 2015), e o livro de Boltanski e Chiapello (2011) sobre o "novo espírito do capitalismo", no qual eles mostram como o regime fordista do capitalismo francês foi capaz de se autorreformar, a partir de certas críticas (notadamente, aquelas que eles agrupam sob a noção de "crítica artista") realizadas por determinados setores da sociedade.
} 
essa pergunta. É aqui que vejo o potencial mais promissor de uma abordagem do capitalismo em termos de prática social.

Um bom desafio para essa abordagem seria, portanto, a de tentar teorizar, assim como lidar criticamente, com isso que aparece como uma criatividade ou uma imaginação tipicamente capitalistas, considerando a dimensão da prática social, o modo específico como, em cada contexto, os portadores dessas práticas carregam, reproduzem, absorvem e renovam os imperativos dos capital. Isto é, teríamos aqui uma abordagem que não desconsidera as capacidades e habilidades - socialmente produzidas - dos atores capitalistas e que seria capaz de captar a riqueza dos recursos e, por assim dizer, do próprio horizonte de sentido desses que constituem, para usar palavras de Marx, o capital personificado ou encarnado.

No caso daquilo que estou tentando delimitar como prática capitalista, que está estreitamente relacionada com a hybris da dinâmica capitalista, o tipo de interpretação do mundo que ela pressupõe diz respeito a um mundo passível de transformação indefinida, no limite, infinita. Trata-se da pressuposição de um mundo composto de uma substância não apenas abstrata, como salienta Lotz, mas infinitamente plástica, conformável aos fins do processo de acumulação. Ademais, temos o pressuposto interpretativo que concerne à própria capacidade de ação e intervenção humana no mundo, cuja apreciação também não atribui limites claros. A princípio, quando se trata do engajamento em açóes capitalistas, é sempre possível fazer mais e melhor; as metas temporárias, na medida em que são cumpridas, rapidamente são substituídas. O horizonte interpretativo é, assim, o de um mundo infinitamente adaptável e transformável por uma ação potencialmente maximamente eficiente.

Qual o pressuposto, então? De que mais crescimento, mais lucro, mais rendimento, sempre é possível (a isso assistimos constantemente nos noticiários - o horizonte do "progresso" econômico é, em princípio, indeterminado, infinito, e isso não é nem um pouco trivial ou "normal": basta comparar com outros tipos de sociedade). Isso é claramente normativo e idealizante. Por isso, proponho chamar esse télos fundamental da prática capitalista de idealização primária do capital, ou seja, a idealização de uma acumulação sempre maior de capital, sem fim. Claro que essa acumulação incessante nem sempre se realiza, e jamais da maneira mais eficaz, no entanto, ela é sempre pressuposta como télos das açôes. 
É justamente em função desse télos ou idealização primária que temos uma imaginação propriamente capitalista, pois o horizonte interpretativo da prática social capitalista promove inovaçôes constantes. É justamente porque a acumulação nunca tem um termo ou fim, e que o mundo é interpretado como infinitamente plástico, que novas formas de acumulação e exploração devem ser e são efetivamente criadas. Ocorre, ao mesmo tempo, uma espécie de instrumentalização e desenvolvimento das capacidades imaginativas dos atores sociais envolvidos nos processos de acumulação de capital. Em todo caso, a dinâmica capitalista não pode se dar sem os recursos imaginativos dos atores sociais envolvidos nas práticas capitalistas.

A virada prática na teoria social se mostrou um movimento fecundo, para uma reinterpretação de uma série de fenômenos sociais. $\mathrm{O}$ capitalismo não deve constituir uma exceção a isso. Neste artigo, procurei apresentar e discutir criticamente duas tentativas recentes, as quais podem ser aproximadas daquilo que podemos chamar de uma interpretação praxeológica do capitalismo. No primeiro caso, o de Rahel Jaeggi, observamos que ainda falta um aprofundamento maior naquilo que constituiria as normas e interpretaçóes específicas da prática capitalista. No segundo caso, o de Christian Lotz, temos um avanço nesse sentido, ainda que ele não se refira explicitamente ao conceito de prática social e prefira o de esquema ou de transcendental. Todavia, a proposta de Lotz peca, a meu ver, por se aproximar demais de uma leitura sistêmica e absolutista do fenômeno capitalista, não fazendo jus ao movimento de dessubstancializaçáo do social promovido pelo practice turn. Por isso, propus esquematicamente uma abordagem alternativa, que procura dar conta do que chamei de imaginação capitalista.

HORA, L. Capitalism as a social practice? The potentials and challenges of an approximation between the practice turn in social theory and the interpretation of capitalism. Trans/form/ação, Marília, v. 43, n. 3, p. 277-302, Jul./Set., 2020.

\footnotetext{
Abstract: This paper aims to present and discuss recent attempts in social philosophy to analyze and interpret capitalism from a praxeological perspective. The practice turn in social theory sought to overcome the dualism between agency and structure, or between action and system, through the notion of social practice. Is it then possible to interpret capitalism as a specific type of social practice? To try to address this question, I briefly introduce, in a first moment, the practice turn in social
} 
theory. In a second moment, I analyze and discuss Rahel Jaeggi's proposal to conceive the economy as a network of social practices. I then explain and evaluate Christian Lotz's attempt to see money as the key to understanding what he names as "the capitalist schema". Finally, I conclude by drawing attention to the potentials and challenges of interpreting capitalism as a social practice, suggesting that a deeper analysis of specifically capitalist imagination, linking it with the typical plasticity and diversity of capitalism, may help to move forward in this field.

Keywords: social philosophy; capitalism; social practice

\section{REFERÊNCIAS}

AMABLE, Bruno. Les cinq capitalismes : Diversité des systèmes économiques et sociaux dans la mondialisation. Paris: Seuil, 2005.

BOLTANSKI, Luc; CHIAPELLO, Ève. Le nouvel esprit du capitalisme. Paris: Gallimard, 2011.

BOLTANSKI, Luc; THÉVENOT, Laurent. De la justification: les économies de la grandeur. Paris: Gallimard, 1991.

BOYER, Robert. Économie politique des capitalismes. Paris: La Découverte, 2015.

CORCUFF, Philippe. Les nouvelles sociologies: Sociologies contemporaines. Paris: Armand Colin, 2011.

CORREAA, Diogo. Do problema do social ao social como problema: elementos para uma leitura da sociologia pragmática francesa. Revista de ciências sociais - política 8 trabalho, v. 1, n. 40, 11 ago. 2014. Disponível em: <http://periodicos.ufpb.br/index. php/politicaetrabalho/article/view/18140>. Acesso em: 1 jun. 2017.

DA HORA PEREIRA, Leonardo. Dominação abstrata ou concepção abstrata? Considerações sobre a teoria crítica do capitalismo de Moishe Postone. Cadernos De Filosofia Alemã: Crítica e Modernidade, 23(1), 41-61, 2018.

FRASER, Nancy; JAEGGI, Rahel. Capitalism. A conversation in critical theory. Cambridge/Medford: Polity, 2018.

HABER, Stéphane. Renouveau de la philosophie sociale? Esprit, Mars/abril, n. 3, p. 131-149, 1 ago. 2012.

JAEGGI, Rahel. A wide concept of economy: economy as a social practice and the critique of capitalism. In: DEUTSCHER, Penelope; LAFONTm Cristina (orgs.). Critical Theory in Critical Times: Transforming the Global Political and Economic Order. New York: Columbia University Press, 2017, p. 160-180. Versão consultada disponível em https://www.academia.edu/20601920/Economy_as_a_Social_Practice. Acesso em: $01 / 011 / 2015$.

JAPPE, Anselm. Les Aventures de la marchandise: Pour une nouvelle critique de la valeur. Paris: Denoël, 2003. 
JOAS, Hans. La créativité de l'agir. Paris: Ed. du Cerf, 1999.

KURZ, Robert. et al. Vies et mort du capitalisme : Chroniques de la crise. Paris: Nouvelles Editions Lignes, 2011.

LOTZ, Christian. The Capitalist Schema: Time, Money, and the Culture of Abstraction. New York: Lexington Books, 2014.

MARX, Karl. Das Kapital. Kritik der politischen Ökonomie - Band 1: Der Produktionsprozeß des Kapitals. 30. Auflage ed. Berlin: Dietz Verlag, 1986.

POSTONE, Moishe. Time, Labor, and Social Domination: A Reinterpretation of Marx's Critical Theory. Cambridge; New York: Cambridge University Press, 1996.

RECKWITZ, Andreas. Toward a Theory of Social Practices A Development in Culturalist Theorizing. European Journal of Social Theory, v. 5, n. 2, p. 243-263, 1 maio 2002 .

SOHN-RETHEL, Alfred. Geistige und körperliche Arbeit : zur Epistemologie der abendländischen Geschichte. Weinheim: VCH, Acta Humaniora, 1989

VIOULAC, J. La logique totalitaire. Essai sur la crise de l'Occident. Paris: Presses Universitaires de France - PUF, 2013.

VIOULAC, J. L'époque de la technique. Marx, Heidegger et l'accomplissement de la métaphysique. Paris: Presses Universitaires de France - PUF, 2009.

Recebido: $14 / 7 / 2020$

Aceito: $23 / 7 / 2020$ 
HORA, L. 